\title{
The Bio-Film-Its Implications in the Technological Process of Producing Drinking Water and Its Reduction
}

\author{
Daniela Gologan ${ }^{1}$, and Gheorghe Poienariu ${ }^{2}$ \\ ${ }^{1}$ Head of quality and treatment water department WTP-Paltinu-Voila-Romania \\ ${ }^{2}$ Head of operation WTP-Paltinu-Voila-Romania
}

\begin{abstract}
Both pathogenic microbial cells as well as nonpathogenic water are able to adhere to rigid surfaces (settling walls, pipes, filters, tanks) through a matrix forming an exopolymeric astringent film, visible to the eye, generically called bio-film and which contains specific microbial communities. Some organisms in bio-films can accelerate corrosion of some materials types. These corrosion products provide additional habitat for other organisms, forming bio-films The type and the concentration of disinfectant used in water treatment can affect the development of bio-films. For example chlorine is consumed by the bio-film, but not always effectively penetrates the bio-film layer. For these reasons there was developed the complex substance capable to limit and control the bio-film development. This paper presented the results which were obtained when there was used the mixture of solution based on hydrogen peroxide in order to reduce the bio-film in sand filtration in water treatment plant. This solution mixture was spread both in the sand layer and on the wall of filters. After this treatment there were weekly performed the analysis of the layer of the deposits on the filter and filter tank walls, by monitoring the turbidity, the iron related bacteria, the slime bacteria, the pathogenic bacteria of the water cycle and filtering operation for long period ( 250 days)
\end{abstract}

Keywords: drinking water, bio-film, chemical disinfection, biological corrosion

\section{Introduction}

The exo-polymeric astringent film, visible to the eye, generically called bio-film contains specific microbial communities 99\% of living organisms on Earth [1]. This immobile biomass can be a source of contamination and proliferation of microorganisms in technological installation plant and on drinking water networks, and it can accumulate metals, toxic compounds which may cause corrosion of the technological installations (biological corrosion) [1]. The bio-films can create problems in terms of taste, smell and water colour. The cells within bio-films are resistant to $\sim 1000$ times more to antibiotic substances and biocides than the cells in suspension (planktonic cells). Bacteria are the first organisms to colonize the pipe concrete walls surfaces. Once enough organic material adheres to the surface (a process called "conditioning") bacteria can begin to attack. This organic material neutralizes excessive ion load on the surface, which can prevent the bacteria to adhere[1].

A persistent problem is the opportunistic pathogens in bio-films, those pathogens that cause diseases for people with low immune system such as AIDS patients, diabetics, and people with cancer, children and elderly people. The opportunistic pathogens are: Pseudomonas aeruginosa, Legionella pneumophila, Mycobacterium avium. Pseudomonas aeruginosa is a common "pioneer" used in the research about the bio-films [1]. It was found that Pseudomonas cells adhere to stainless steel walls after 30 seconds of exposure [2].

The type and the concentration of disinfectant used can affect the development of bio-films[3]. Residual chlorine is consumed by the bio-film, but not always effectively penetrates the bio-film layer. Some systems that use chlorine or ozone as a disinfectant found out that the bio-film develops and there isn't a restriction of its growth[1]. This happens when organic molecular carbon complexes such as humic or fulvic acids, which are difficult consumed by bacteria, are oxidized by the disinfectants and they are transformed into compounds with smaller molecules that can be more easily assimilated [4]. So chlorine and the ozone in this case help the biofilm, growing the organic matter necessary in proliferation of the bio-film organisms. To be effective the chlorine and the chemicals should be added in high concentration and the contact time must be increased.

Worldwide-complex solutions have appeared, mixtures of organic substances, powerful bactericides, surfactants that have a greater efficiency on the bio-film, because both fail to destroy the protective layer of the bio-film colonies as well as at the cellular level. This paper presents the results obtained when there was used 
the mixture of solution based on hydrogen peroxide[5]- to reduce the bio-film in sand filtration on treatment plant. This solution is manufactured in Germany by Mosslein GMBH.

\section{Experimental phase}

\subsection{The test phase}

The mixture solution was tested in Paltinu -Voila Plant on quartz sand filter. The aria of this filter is $72 \mathrm{mp}$ and the height of the quartz sand layer is $1.1 \mathrm{~m}$. The filter had visible deposits on the walls of both bacteria and algae, the filter-sand filter layer had persistent depositions of sulphur and iron bacteria and a layer of calcium carbonate and magnesium -Figure 1.

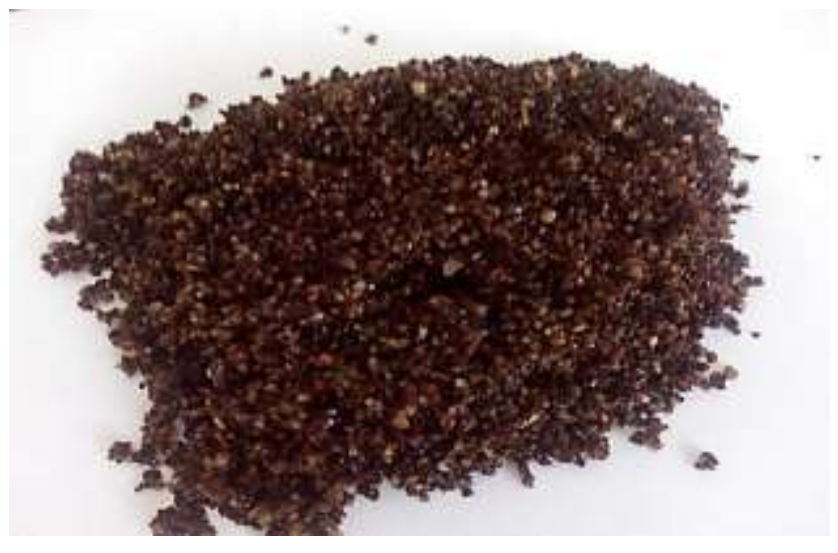

Fig. 1: The quartz sand before the treatment

The deposits on the sand grains leads in time to round sand grains that has the effect of lowering filtration efficiency by reducing the attraction forces that the grains of sand have on the colloidal particles in water.

On the other hand these entire bio-film layers deposited on the walls as well on the grains of sand are a source of growth and multiplication of pathogenic bacteria and have the effect of increasing the dose of chlorine for disinfection.

For the beginning of the treatment, the mixture solution was sprayed on filter walls and sand surface layerfigure 2 .

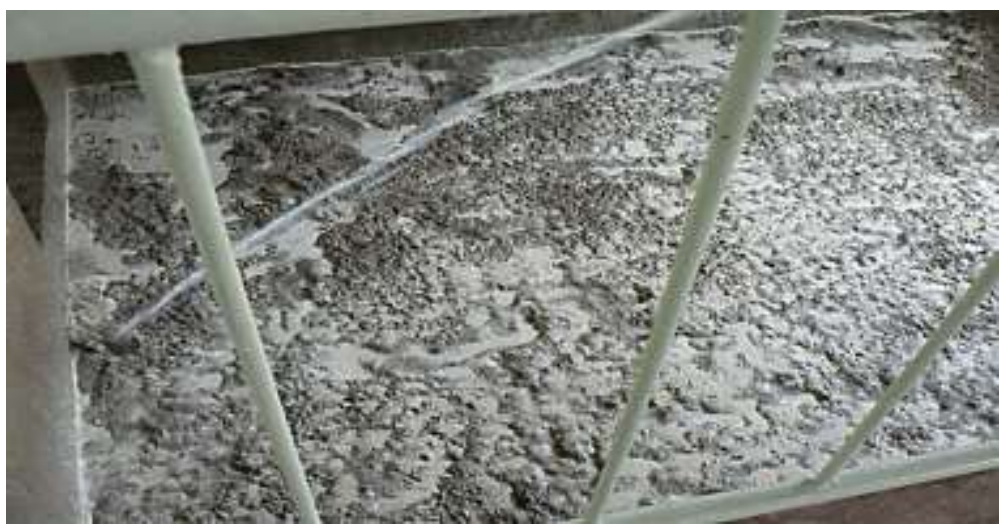

Fig. 2: Spraying the solution on quartz sand filter

After spraying the solution, the rest phase was from 12 to $24 \mathrm{~h}$, depending on the deposits on grain of sand. When time of rest has passed, the filter was washed with water and air reflow.The operation is repeated 2-3 times. 


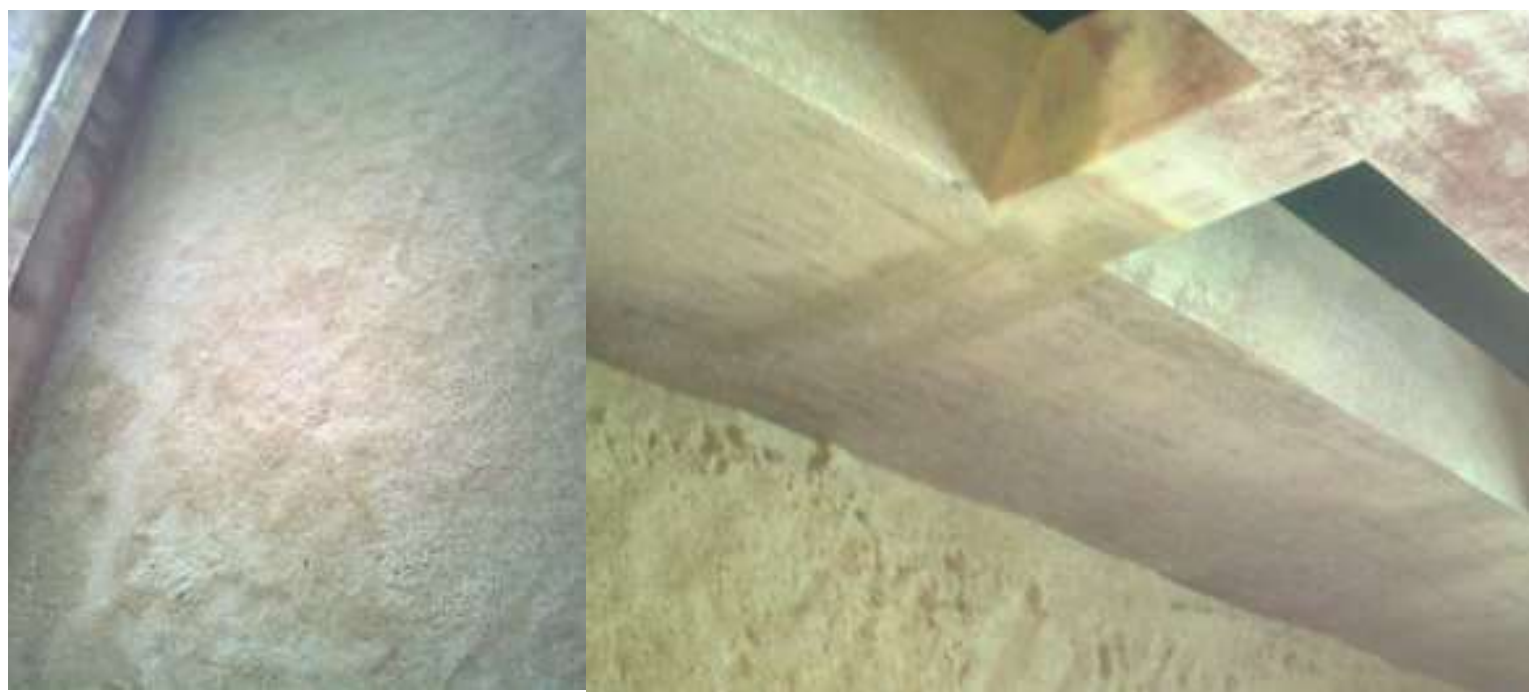

Fig. 3: The quartz sand after finish the treatment

\subsection{The results}

Also after this treatment there were weekly performed the analysis of the layer of the deposits on the filter and filter tank walls, by monitoring the turbidity of the water cycle and filtering operation and the bacteria content in filtered water.

To illustrate the long-term behaviour, I have chosen to compare three filters: the first ones which were treated with complex mixture solution, 2nd which were treated with chlorinated lime and water jet washing of the tank walls and the 3 nd were without any treatment. After 250 days of treatment, the comparative results for these filters are shown below:

The medium operating cycle of the filter to which the treatment has been applied is $\sim 35 \%$ higher than the filters to which were applied the regular treatment - lime chlorine, and 58\% higher than the filter to which was not applied any treatment- figure 4

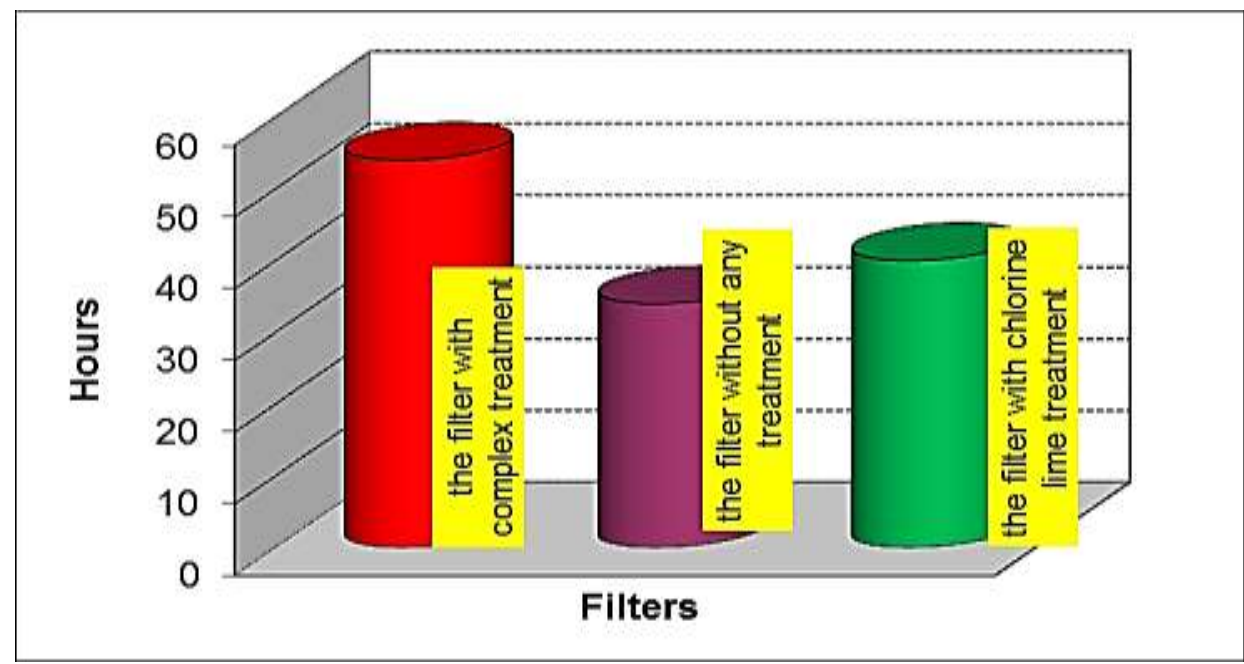

Fig. 4: Average filter cycle after 250 days of complex treatment

The terms of average turbidity of the filter medium cycle, shows that the turbidity was lower in filtered water from the treated filter of all the monitored filters. The average turbidity for filtration cycle decreased for the treated filter by 53\% compared to the filter with chlorine lime treatment and by $97 \%$ compared to the filter without any treatment- Figure 5. 


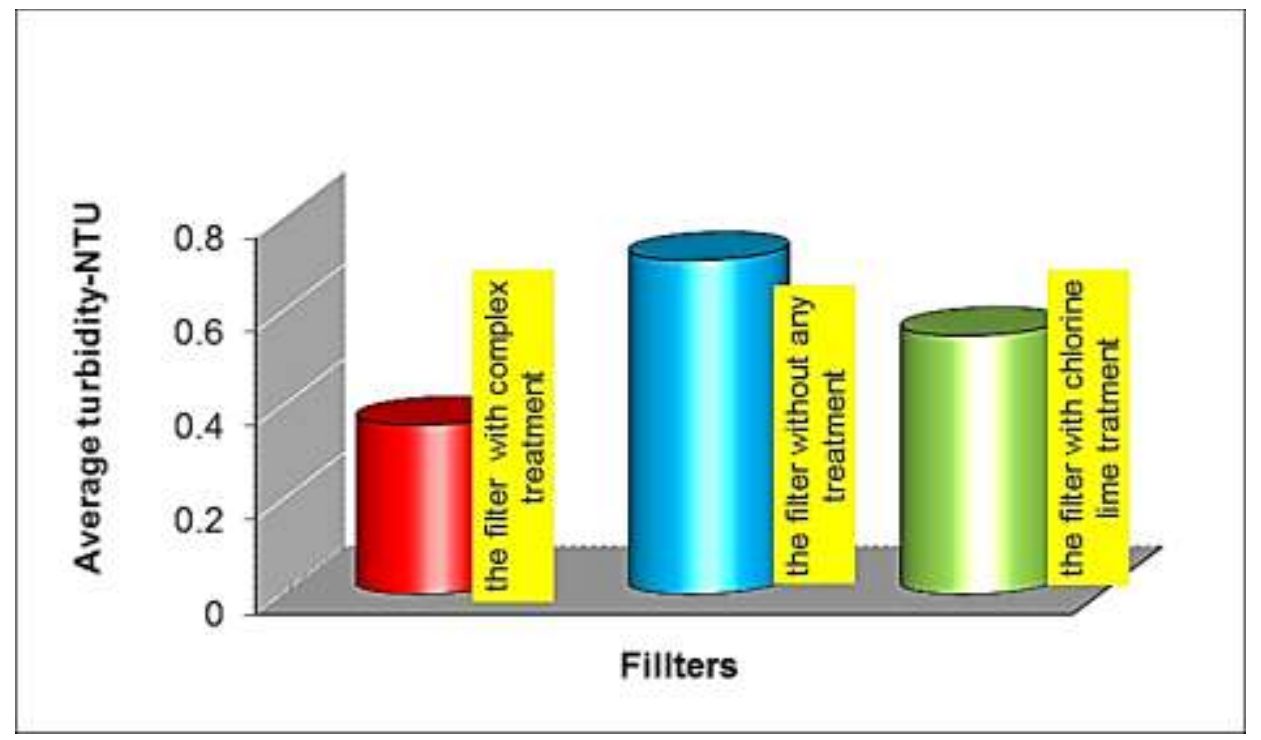

Fig. 5: Average turbidity of filter after 250 days of treatment

In the treated filter after a period of eight months iron-bacteria concentration is 4.6 times lower. Iron bacteria are the main group involved in the corrosion process, so they form deposits on pipes and on the granules filter layer being a very important element in the bio-films proliferation -figure 6

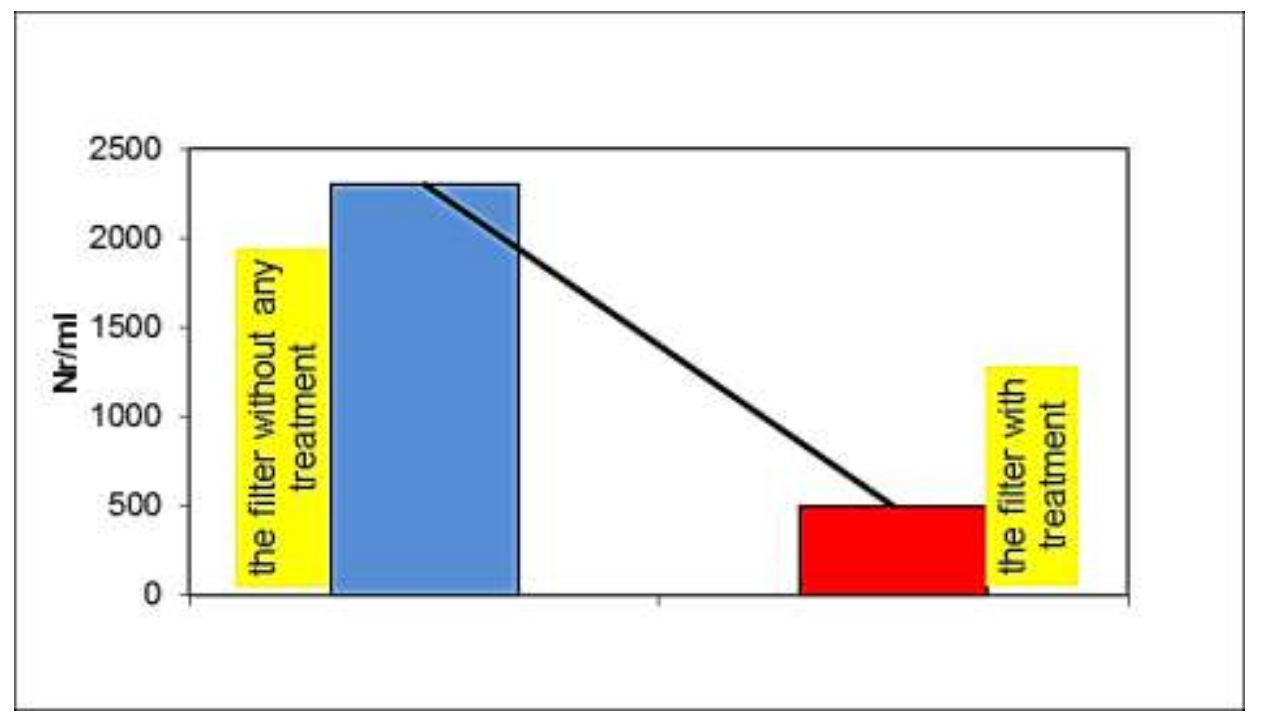

Fig. 6: Iron related bacteria after 250 days of treatment

In terms of content of the pathogenic enteric bacteria, the filter with treatment shows 3.9 times less organisms than the filter without any treatment -Figure 7. 


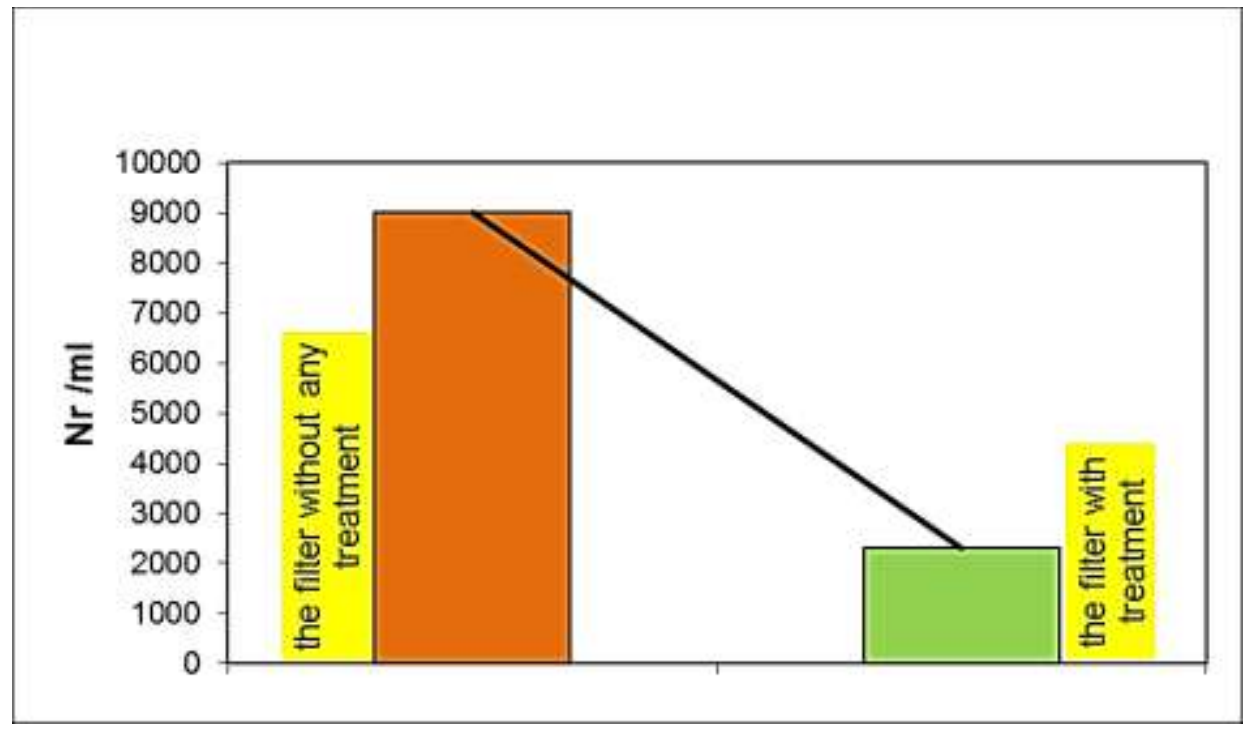

Fig. 7: Enteric pathogenic bacteria after 250 days of treatment

The treated filter, bio-film-forming bacteria are present in a concentration of 3.6 times lower than if the filter was not applied to any treatment- figure 8

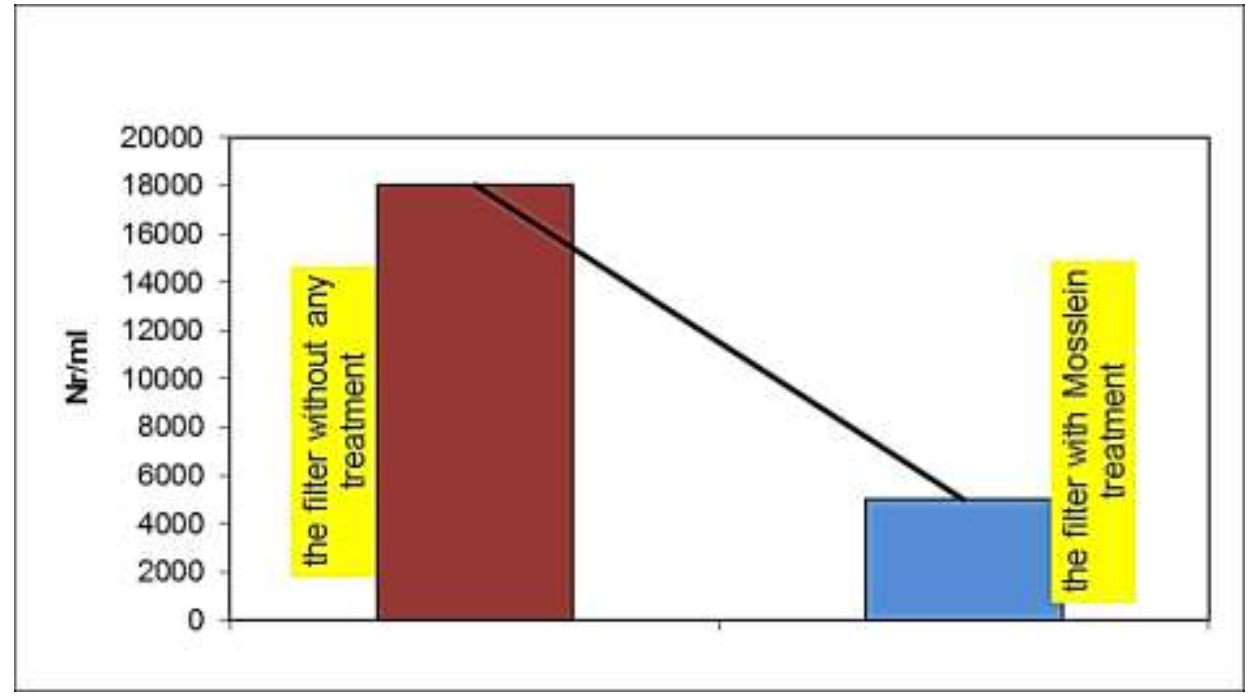

Fig. 8: Slime forming bacteria after 250 days of treatment

\subsection{Conclusion}

The conclusion of these comparative data is that treatment with complex solutions net improves water quality, reduces water consumption of washing technology due to increased filtering cycle, provides reconditioning of the quartz sand filter layer.

The treatment with lime and chlorine must be done every month and has no effect - the damaged sand layer in the filter must be changed.

The complex mixture solutions had a triple role: removal of the bio-film on the walls, reconditioning of the filter layer by removing deposits on the grains, removing the bio-film from the inaccessible places-: creepiness plates, creepiness, filtered water tanks in filters, pipes connecting the pipe gallery.

The advantage of this solution is that it also operates in inaccessible places, such as the layer creepiness boards, filtered water tank.

Using this solutions will increase efficiency and reduce the bacterial load of the filtering performance of the filters, disinfecting inaccessible places, decreasing the consumption technology. 
In tank-removal of the bio-film there are eliminated the tedious manual operations which are done with the brush to eliminate the bio-film, then the operation of making lime chlorine shock treatment and after that of neutralizing it with sodium thiosulfate.

\section{Acknowledgements}

I wish to thank my colleagues for help, management of WTP Paltinu for material support and Mosslein GMBH for trust.

\section{References}

[1] Dreeszen P.H -The key understanding and controlling bacterial growth in drinking water systems, Second Edition 2003-Edstrom Industries, 4230-DS3100 10/03 IH

[2] VanHaecke, E.; Remon, J-P; Moors, M.; Raes, F.; DeRudder, D.; VanPeteghem, A. "Kinetics of Pseudomonas aeruginosa Adhesion to 304 and 316-L Stainless Steel: Role of Cell SurfaceHydrophobicity", Applied and Environmental Microbiology 56(3), pp. 788-795 (March 1990).

[3] LeChevallier, M.W.; Cawthon, C.D.; Lee, R.G. "Inactivation of Biofilm Bacteria", Applied and Environmental Microbiology 54(10), pp. 2492-2499 (October 1988).

[4] Borenstein, S.B., Microbiologically Influenced Corrosion Handbook, Industrial Press Inc., New York (1994).

[5] Mittelman, M.W. "Biological Fouling of Purified-Water Systems: Part 3, Treatment”, Microcontamination 4(1), pp. 30-40, 70 (January 1986). 